\title{
Systemic Colonization by Metarhizium robertsii Enhances Cover Crop Growth
}

\author{
Imtiaz Ahmad ${ }^{1, *(\mathbb{D}}$, María del Mar Jiménez-Gasco ${ }^{2}$, Dawn S. Luthe ${ }^{3}$ and Mary E. Barbercheck ${ }^{1}$ (D) \\ 1 Department of Entomology, The Pennsylvania State University, University Park, PA 16802, USA; \\ meb34@psu.edu \\ 2 Department of Plant Pathology and Environmental Microbiology, The Pennsylvania State University, \\ University Park, PA 16802, USA; mxj22@psu.edu \\ 3 Department of Plant Science, The Pennsylvania State University, University Park, PA 16802, USA; \\ dsluthe@icloud.com \\ * Correspondence: ixa12@psu.edu; Tel.: +1-814-812-6455
}

Received: 29 April 2020; Accepted: 15 May 2020; Published: 17 May 2020

\begin{abstract}
Fungi in the genus Metarhizium (Hypocreales: Clavicipitaceae) are insect pathogens that can establish as endophytes and can benefit their host plant. In field experiments, we observed a positive correlation between the prevalence of $M$. robertsii and legume cover crops, and a negative relationship with brassicaceous cover crops and with increasing proportion of cereal rye in mixtures. Here, we report the effects of endophytic $M$. robertsii on three cover crop species under greenhouse conditions. We inoculated seeds of Austrian winter pea (Pisum sativum L., AWP), cereal rye (Secale cereale L.), and winter canola (Brassica napus L.) with conidia of $M$. robertsii to assess the effects of endophytic colonization on cover crop growth. We recovered M. robertsii from $59 \%, 46 \%$, and $39 \%$ of seed-inoculated AWP, cereal rye, and canola plants, respectively. Endophytic M. robertsii significantly increased height and above-ground biomass of AWP and cereal rye but did not affect chlorophyll content of any of the cover crop species. Among inoculated plants from which we recovered $M$. robertsii, above-ground biomass of AWP was positively correlated with the proportion of colonized root but not leaf tissue sections. Our results suggest that winter cover crops may help to conserve Metarhizium spp. in annual cropping systems.
\end{abstract}

Keywords: cover crops; endophytes; fungal entomopathogens; Metarhizium robertsii; plant growth promotion; plant-microbe interactions

\section{Introduction}

Several hypocrealean entomopathogenic fungi (EPF) commonly occur in soil [1] and in addition to infecting insects directly, can exist as rhizosphere colonizers and endophytes that provide multiple benefits in agroecosystems [2,3]. These benefits include plant growth promotion through nutrient transfers [4-6], plant disease suppression [7-9], and insect growth suppression [10-12]. Entomopathogenic fungi in the genus Metarhizium (Metschnikoff) Sorokin (Order Hypocreales: Family Clavicipitaceae) have a broad arthropod host range and are well-adapted to soil in agricultural systems [13-15]. Multiple species of Metarhizium are able to colonize the roots of many plant species, including switchgrass, haricot bean, tomato, wheat, and soybean [6,16-20]. Colonization of common bean by Metarhizium robertsii occurred through a prolonged rhizoplane colonization phase followed by transient low-level colonization of roots that persisted throughout the plant life cycle [21].

Plant growth promoting effects associated with endophytic colonization have been observed for multiple species of Metarhizium in tomato [18], maize [10,22], soybean [23], potato [24], cassava [19] and sweet pepper [25]. Application of M. anisopliae promoted the early development of peanut 
roots [26]. Inoculation with $M$. robertsii promoted lateral root growth and development of root hairs Arabidopsis thaliana seedlings in part through an auxin-dependent mechanism [27]. Soil drenching with M. brunneum resulted in an increase in sweet pepper growth parameters at 7- and 35-days post-inoculation [28]. Maize seeds inoculation with M. anisopliae was associated with increased stand density, and stalk and foliage fresh weight [29]. The authors attributed these effects to wireworm control and suggested that seed inoculation with $M$. anisopliae may be a novel method to increase stand density and yield of maize.

Rhizosphere-associated microbial communities are strongly influenced by plant species and soil characteristics in an agroecosystem [30,31]. Diverse plant species provide different species-specific resources such as metabolites, root exudates and other beneficial rhizosphere-associated compounds [32,33]. Plant species can also influence the occurrence of Metarhizium spp. [34]. For example, Wyrebek et al. [35] reported specificity of Metarhizium spp. in the rhizosphere and tissues of grasses. However, others have found no specificity in M. robertsii-plant associations [36].

Winter cover crops are grown between summer cash crops for benefits to soil and plant health. Winter cover crops provide benefits including, but not limited to, soil conservation, nutrient supply and retention, pest suppression and increased cash crop yield [37-41]. Growers are interested in using multi-species cover crop mixtures to provide a wide range of short- and long-term ecosystem services [42]. In an organically-managed cover crop-soybean-cover crop-maize rotation, M. anisopliae detection was greater in a cover crop mixture of timothy and red clover compared with a cereal rye and hairy vetch mixture [43]. In a field experiment to determine the effects of winter cover crop diversity in an annual cropping system on a variety of ecosystems services, detection of M. robertsii was lower in treatments with brassica cover crops as compared to those with legume cover crops [44]. Survival of conidia of formulated M. anisopliae applied to cereal rye and oat cover crops in a sugarbeet production system was greater in oat than in cereal rye, and the authors suggested that allelopathic compounds from cereal rye may have suppressed $M$. anisopliae [45].

Relatively fewer studies have reported the use of cover crops for the conservation of entomopathogens for biological control $[13,46]$. In this study, our goal was to determine the relative ability of $M$. robertsii isolated from soil from a field experiment [42] to colonize commonly-grown winter cover crop species. We tested the effects of $M$. robertsii inoculation of seeds of three cover crop species in three plant functional groups that were associated with different levels of detection of M. robertsii in the field: Austrian winter pea (Pisum sativum L. 'Arvika'), cereal rye (Secale cereale L. 'Aroostook'), and winter canola (Brassica napus L. 'Wichita') [44]. The specific objectives of this study were to assess: (1) the degree of endophytic colonization of plants by M. robertsii; (2) the tissue location of endophytic colonization of $M$. robertsii in cover crops grown from inoculated seeds; and (3) the effects of endophytic colonization by $M$. robertsii on cover crop growth. Based on our previous field studies [44], we hypothesized that: (1) colonization of Austrian winter pea would be greater than in cereal rye, and that colonization of canola would be lowest; (2) colonization of roots would be greater than that of foliage; and (3) growth promoting effects would be positively related to the intensity of colonization as determined by number of tissue sections colonized.

\section{Materials and Methods}

\subsection{Fungal Inoculum}

We used an isolate of $M$. robertsii J. F. Bischoff, Rehner and Humber originally collected from an annual agronomic cropping system experiment [42]. The field site was located at the Russell E. Larson Research and Education Center at Rock Springs, Pennsylvania, USA ( $43^{\prime} 40^{\circ} \mathrm{N}, 55^{\prime} 77^{\circ} \mathrm{W}$, $350 \mathrm{~m}$ elevation) and managed in accordance with the USDA National Organic Standards [47], with no synthetic pesticide or fertilizer application [44]. We obtained the isolate of M. robertsii used in this experiment by sentinel insect baiting with larvae of Galleria mellonella of soil samples from an experimental plot containing winter canola (Brassica napus L. 'Wichita') [48]. We obtained pure cultures 
of this $M$. robertsii isolate from sporulating cadavers by culturing on dodine-free semi-selective CTC medium [49]. We confirmed the identity of fungi recovered from inoculated plants in the current experiment as M. robertsii by morphological and molecular characteristics [50,51]. We stored conidia produced and harvested from single spore cultures on beads (Pro-Lab Diagnostics Microbank ${ }^{\mathrm{TM}}$ Bacterial and Fungal Preservation System) at $-80^{\circ} \mathrm{C}$ for use in the experiments described herein. We submitted the translation elongation factor 1- $\alpha$ (TEF1- $\alpha$ ) sequence of the isolate to NCBI GenBank under accession number MK988559 and the single spore isolated culture to The Agricultural Research Service Collection of Entomopathogenic Fungal Cultures (ARSEF) under the accession number 14325.

To produce inoculum for experiments, we transferred beads from cryovials aseptically and plated them onto $100 \mathrm{~mm} \times 15 \mathrm{~mm}$ Petri plates containing dodine-free semi-selective CTC medium [49]. The plates were then incubated at $25 \pm 2{ }^{\circ} \mathrm{C}$ in the dark for $14-18$ days. We harvested the conidia under aseptic conditions by scraping the agar surface with a sterile stainless-steel mini spatula and suspended them in a sterile $0.05 \%$ aqueous solution $(v / v)$ of Triton ${ }^{\mathrm{TM}}$ X-100 (Dow Chemical Co., Midland, MI, USA). We homogenized the conidial suspension by vigorously shaking for one minute in sterile capped $50 \mathrm{~mL}$ centrifuge tubes. We filtered the conidial suspension through four layers of sterile cheese cloth to separate the mycelial fragments from conidia. We determined the concentration of the stock conidial suspension under a compound microscope at 400× magnification with a Neubauer hemocytometer and adjusted the concentration to $1 \times 10^{8}$ conidia $\mathrm{mL}^{-1}$ for seed inoculation. To determine the viability of the conidia we assessed the ability of conidia to form a germ tube by plating $80 \mu \mathrm{L}$ of the conidial suspension onto a Petri plate $(100 \mathrm{~mm} \times 15 \mathrm{~mm})$ containing CTC medium and stored in dark at $25 \pm 2{ }^{\circ} \mathrm{C}$ for $24 \mathrm{~h}$. We assessed the percent viability by randomly counting 200 conidia at $400 \times$ magnification and considered conidia viable if hyphae were visible or the germ tube was at least twice the length of the conidium. The germination rate of the conidial suspensions used in experiments was greater than $90 \%$.

\subsection{Seed Surface Sterilization and Inoculation}

We surface-sterilized seeds of Austrian winter pea (AWP), cereal rye, and canola in a sterile laminar flow hood by immersion in $0.5 \%$ sodium hypochlorite for two minutes followed by soaking in $70 \%$ ethanol for two minutes and rinsing three times in sterile distilled water [52]. To confirm successful surface sterilization, we placed three randomly selected seeds onto a Petri plate $(100 \mathrm{~mm} \times$ $15 \mathrm{~mm}$ ) containing CTC medium. We also plated $80 \mu \mathrm{L}$ of the final rinse water onto $100 \mathrm{~mm}$ Petri plates containing Sabouraud dextrose agar and yeast (SDAY) and incubated them in darkness at $25 \pm 2{ }^{\circ} \mathrm{C}$ for 10 days. After surface sterilization, we air-dried the seeds under sterile conditions in a laminar flow hood for $5 \mathrm{~min}$ and stored them at $4{ }^{\circ} \mathrm{C}$ for $24 \mathrm{~h}$ for use in experiments.

Surface-sterilized seeds were placed in $100 \mathrm{~mL}$ of freshly prepared conidial suspension $\left(1 \times 10^{8}\right.$ conidia $\mathrm{mL}^{-1}$ ) of $M$. robertsii in a $250 \mathrm{~mL}$ sterile beaker covered with aluminum foil. We placed control seeds in a $250 \mathrm{~mL}$ beaker containing $100 \mathrm{~mL}$ of $0.05 \%$ Triton X-100 aqueous solution and covered it with aluminum foil. We then placed both the inoculated and control beakers on a shaker at $10 \mathrm{rpm}$ for $2 \mathrm{~h}$ to accomplish inoculation.

\subsection{Plant Growth and Experimental Design}

We prepared plant growth medium by mixing steamed field soil and potting mix (Vigoro Organic Potting Mix) in a 1:1 ratio by volume. To reduce contaminant microbial growth and interactions, we steamed the growth medium twice for $2 \mathrm{~h}$ at $121^{\circ} \mathrm{C}$ in a steam sterilizer. We waited $48 \mathrm{~h}$ after steaming the medium before using it in experiments to avoid toxicity of the soil to plants. We placed one seed inoculated with $M$. robertsii, or a control seed at a depth of $\sim 2.5 \mathrm{~cm}$ in separate steamed $15 \mathrm{~cm}$ diameter $\times 14.7 \mathrm{~cm}$ tall plastic plant pots containing the prepared growth medium by using separate sterile spatulas for each treatment group. We planted the control seeds before the M. robertsii-inoculated seeds to avoid cross-contamination. We placed the prepared pots randomly on a greenhouse bench with 16L:8D photoperiod at $25 \pm 3^{\circ} \mathrm{C}$ and provided water as needed. We repeated the experiment 
three times for AWP and four times for cereal rye and canola. For AWP, in the first, second, and third trial, we grew 10, 16, and $26 \mathrm{M}$. robertsii-inoculated plants, and 10, 15, and 34 control plants, respectively. For cereal rye, in the first, second, third, and fourth trials, we grew 5, 9, 16, and $38 \mathrm{M}$. robertsii-inoculated plants, and 5, 10, 15, and 44 plants control plants, respectively. For canola, in the first, second, third, and fourth trials, we grew 4, 7, 15, and $25 \mathrm{M}$. robertsii-inoculated plants, and 5, 8, 15, and 20 control plants, respectively (Table S1).

\subsection{Evaluation of Plant Endophytic Colonization}

To evaluate the endophytic colonization of plants by M. robertsii we sampled treated and control plants at 30 days after germination (DAG). From each plant, we randomly removed a newly emerged true leaf and two 5-cm long root sections using sterile scissors. We wiped the removed leaves with 70\% ethanol using Kimwipes ${ }^{\mathrm{TM}}$ and rinsed excised roots with tap water to remove loosely attached soil. We stored the excised plant sections individually at $4{ }^{\circ} \mathrm{C}$ in $17.7 \mathrm{~cm} \times 18.8 \mathrm{~cm}$ labelled Ziploc ${ }^{\circledR}$ bags for further processing. We surface-sterilized the excised leaf and root sections by submerging in $0.5 \%$ sodium hypochlorite for three minutes followed by $70 \%$ ethanol for two minutes, followed by serially rinsing three times in sterile deionized water. To confirm the effectiveness of tissue sterilization, we plated $80 \mu \mathrm{L}$ of the final rinse water onto CTC medium and kept the dishes at $25 \pm 2{ }^{\circ} \mathrm{C}$ for 10 days in darkness. The surface-sterilized leaf and root tissues were dried on a sterile paper towel. We cut off the $\sim 1 \mathrm{~mm}$ outer edges of the surface-sterilized leaf and ends of the root tissues using sterile dissecting scissors to remove dead cells. We cut each leaf into $6 \mathrm{~mm} \times 6 \mathrm{~mm}$ sections and each root into $6 \mathrm{~mm}$-long sections so that each plant generated six leaf and six root sections. We plated each tissue type from each plant in a labeled Petri dish prepared with CTC medium by pressing the tissue flat against the surface of the medium. The plates were incubated in the dark at $25 \pm 2{ }^{\circ} \mathrm{C}$ for 14 days to allow endophytic $M$. robertsii growth to emerge from the plant tissue. We identified $M$. robertsii by characteristic white hyphal growth and dark green conidia visually, and under magnification as needed. In our assessment of frequency of tissue colonization, we did not count microbial growth suspected to be other species. To confirm the molecular identity of fungal isolates emerging from the plant sections, we extracted DNA from fungal mycelium produced in $50 \mathrm{~mL}$ sterile potato dextrose broth (PDB, 2.4\%) [53], and stored at $4{ }^{\circ} \mathrm{C}$ for short-term or $-20{ }^{\circ} \mathrm{C}$ for long-term storage. We performed PCR amplification using forward (EF-1T) and reverse primers (EF-2T) to amplify the intron-rich $5^{\prime}$ portion of translation elongation factor-1 $\alpha\left(5^{\prime}\right.$-TEF) locus [51]. We cleaned the PCR products by digestion with Exo-SapIT ${ }^{\circledR}$ (Affymetrix, Santa Clara, CA, USA) and submitted the products to the Pennsylvania State University Genomics Core Facility for Sanger sequencing. The sequences were compared and analyzed with reference sequences by using the BLASTn tool provided by NCBI. We aligned the sequences using ClustalW and performed phylogenetic analysis using the maximum likelihood method to determine the identity of Metarhizium species and we confirmed all the isolates as M. robertsii.

For AWP, from the three replicated trials, we plated 354 root and 354 leaf sections from 59 control plants, and we plated 312 root and 312 leaf sections from 52 AWP plants grown from $M$. robertsii-inoculated seeds. For cereal rye plants from four replicated trials, we plated 444 root and 444 leaf sections from 74 control plants, and we plated 408 root and 408 leaf sections from 68 plants grown from M. robertsii-inoculated seeds. For canola, from four replicated trials, we plated 288 root sections and 288 leaf sections from 48 control plants and 306 root and 306 leaf sections from $51 \mathrm{M}$. robertsii-inoculated plants (Table S1).

We will refer to control plants as 'Not Inoculated' plants because their seeds were not inoculated with $M$. robertsii conidial suspension. M. robertsii-inoculated plants from which we recovered or did not recover M. robertsii were categorized as 'Inoculated and Detected' or 'Inoculated and Not Detected', respectively. We considered a plant to be endophytically colonized when we observed growth of $M$. robertsii from one or more root or leaf sections of a plant. We calculated proportion endophytic colonization of plants by dividing total number of plants with root, leaf, or both root and leaf colonization by total number of M. robertsii-inoculated plants. We determined the relative 
proportion endophytic colonization by plant tissue type for each cover crop by dividing the total number of root or leaf tissues which produced $M$. robertsii growth by total number of leaf or root tissues that were plated onto CTC medium.

\subsection{Plant Response to Inoculation with M. robertsii}

We measured endophytic colonization, height, and chlorophyll content of plants in all trials, whereas we measured plant above-ground biomass in the second and third experiment for AWP and third and fourth experiment for cereal rye and canola. For all parameters, we measured the control plants before the $M$. robertsii-inoculated plants to avoid potential cross-contamination. We measured plant height $(\mathrm{cm})$ from the base of the plant to the tip of the longest fully emerged true leaf at 30 DAG. We measured the total chlorophyll content (SPAD units) of the emerged true leaf by using a SPAD-502 Plus Chlorophyll Meter (Konica Minolta, Japan). We measured chlorophyll from three different true leaves of each plant. Between each treatment, the ruler and chlorophyll meter were wiped with $70 \%$ ethanol using Kimwipes ${ }^{\mathrm{TM}}$ to avoid contamination. We measured plant above-ground biomass by cutting the plant at the soil-plant interface with clean scissors. We placed the plant biomass in dried, pre-weighed brown paper bags, and oven-dried them at $60^{\circ} \mathrm{C}$ for $10-14$ days, when biomass was weighed using a digital balance.

\subsection{Statistical Analyses}

We performed all analyses in JMP ${ }^{\circledR}$ Pro 13.2.0 (SAS Institute Inc., Cary, NC, USA, 1989-2007) unless otherwise stated. We used mixed model ANOVA to determine the degree of endophytic colonization among cover crop species, degree of endophytic colonization in different plant tissues within and among cover crop species, plant height, chlorophyll content and above-ground biomass. To determine endophytic colonization of cover crop species, we analyzed endophytic colonization for 'leaf only', 'root only' and 'both leaf and root' groups for each cover crop species separately. To determine endophytic colonization for a specific tissue, we analyzed 'root' or 'leaf' endophytic colonization for each cover crop species separately. We designated all treatment variables as fixed factors and block as a random factor. When the model was significant, we used Tukey's Honest Significant Difference post-hoc test as pairwise tests of means between each treatment and considered analysis significant at $p<0.05$. We conducted regression analyses to assess the relationship between the proportion of M. robertsii-colonized root and leaf sections per plant and plant growth parameters, using proportion of colonized tissue sections as the explanatory variable and plant growth measures as response variable. For all analyses, we transformed proportions using square root arcsine transformation to meet assumptions of normality, equality of variances and to reduce heterogeneity of variances [54]. Data presented in figures and tables are not transformed.

\section{Results}

\subsection{Endophytic Colonization of Plants and Tissue Location}

We did not detect $M$. robertsii from any of the non-inoculated control plants for any of the experiments (data not shown). Therefore, we consider it most likely that detection of M. robertsii in treated plants was due to systemic colonization from the treated seed. We recovered $M$. robertsii from AWP $(58.72 \pm 0.62 \% ; n=52)$, cereal rye $(46.45 \pm 3.91 \% ; n=68)$, and canola $(39.05 \pm 3.74 \% ; n=51)$ plants grown from inoculated seeds. When we compared among cover crop species, we found greater endophytic colonization in AWP than in cereal rye and canola. There was no difference in endophytic colonization between canola and cereal rye $\left(p<0.03, F_{2,91}=3.8, n=94\right)$. Therefore, our hypothesis that colonization of AWP would be greater than in cereal rye, and that colonization of canola would be lowest was partially supported.

Our hypothesis that we would detect colonization more frequently in roots compared to foliage was partially supported. Out of 30 AWP plants in the group 'Inoculated and Detected', we detected 
endophytic colonization only in leaf tissue in 7 plants $(21.75 \pm 3.54 \%)$, only in root tissue in 15 plants $(50.95 \pm 4.97 \%)$, and endophytic colonization of both leaf and root tissues in 8 plants $(27.03 \pm 3.9 \%)$. Out of 38 cereal rye plants in the group 'Inoculated and Detected', we detected endophytic colonization only in leaf tissue in 5 plants $(11.51 \pm 7.3 \%)$, only in root tissue in 15 plants $(53.41 \pm 6.76 \%)$, and endophytic colonization of both leaf and root tissues in 18 plants $(35.08 \pm 12.93 \%)$. Out of 26 canola plants in the group 'Inoculated and Detected', we detected endophytic colonization only in leaf tissue in 4 plants $(19.72 \pm 6.8 \%)$, only in root tissue in 15 plants $(51.95 \pm 9.33 \%)$, and endophytic colonization both in leaf and root tissues in 7 plants $(28.33 \pm 2.55 \%)$. There was no significant difference among cover crop species in the proportion of plants from which we detected endophytic colonization only in leaf tissue $\left(p<0.63, F_{2,5}=0.52, n=9\right)$, only in root tissue $\left(p<0.94, F_{2,4}=0.06, n=9\right)$, or both leaf and root tissue $\left(p<0.61, F_{2,4}=0.57, n=9\right)$. Among different tissues within a cover crop species, the proportion of endophytic colonization only from root was significantly higher in AWP plants compared to recovery only from leaf tissue, whereas the recovery from both leaf and root tissues was not different than recovery from only leaf or only root tissues $\left(p<0.03, F_{2,4}=9, n=9\right)$. The proportion of endophytic colonization among tissues was not different in cereal rye $\left(p<0.15, F_{2,4}=3.19, n=9\right)$ or canola $(p<0.11$, $\left.F_{2,4}=3.97, n=9\right)$ (Figure 1).

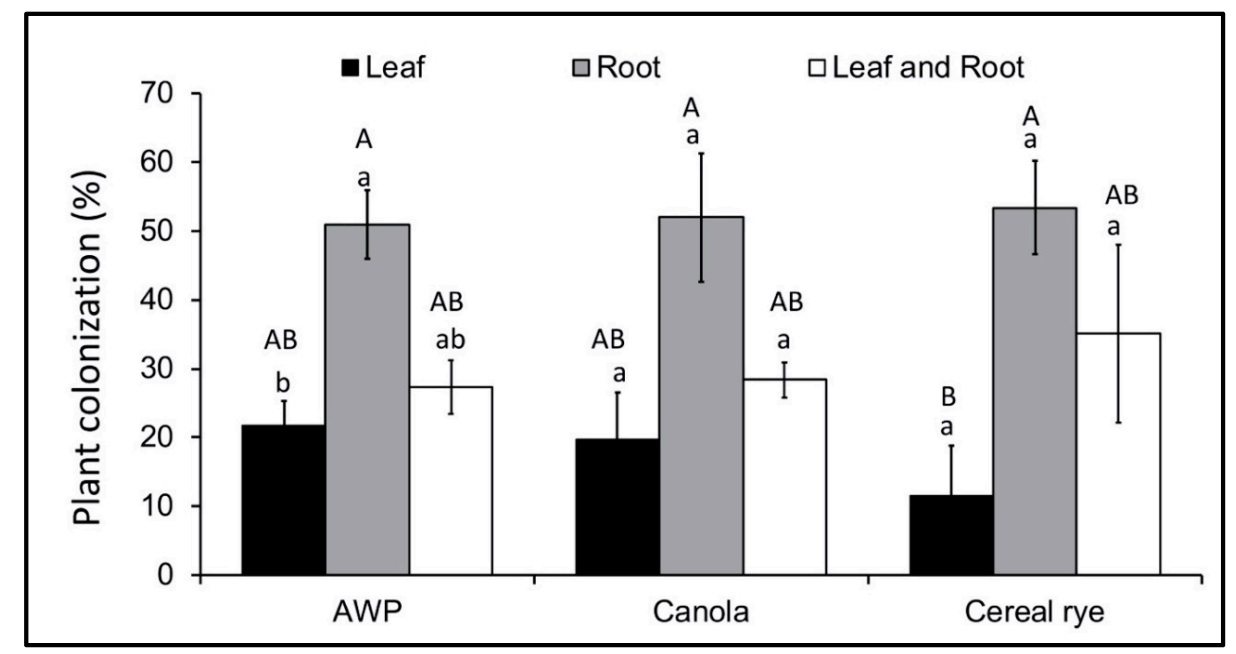

Figure 1. Percentage of plants grown from $M$. robertsii-inoculated seeds from which endophytic growth was detected in only leaf, only root or both leaf and root tissues in Austrian winter pea (AWP) $(n=30)$, cereal rye $(n=38)$ and canola $(n=26)$. The error bars represent \pm standard error of the mean. The lowercase letters show the difference for leaf only, root only and both leaf and root within a cover crop species. The uppercase letters show the differences for leaf only, root only and both leaf and root groups among cover crop species. The bars sharing common letters are not significantly different at $p=0.05$.

Within a cover crop species, endophytic colonization of root tissue was greater than colonization of leaf tissue in AWP $\left(p=0.007, F_{1,28}=8.23, n=30\right)$ and canola $\left(p=0.02, F_{1,24}=6.72, n=26\right)$, and was not different in cereal rye ( $\left.p=0.43, F_{1,36}=0.64, n=38\right)$. Among the cover crop species, endophytic colonization of root tissue was greater in AWP than in cereal rye and canola, while there was no difference between canola and cereal rye $\left(p=0.004, F_{2,74}=5.89, n=78\right)$. When compared among cover crop species, endophytic colonization of leaf tissue was greater in AWP and cereal rye than in canola, whereas colonization of leaf tissue of AWP and cereal rye was not different $\left(p=0.03, F_{2,90}=3.81, n=94\right)$ (Figure 2). 


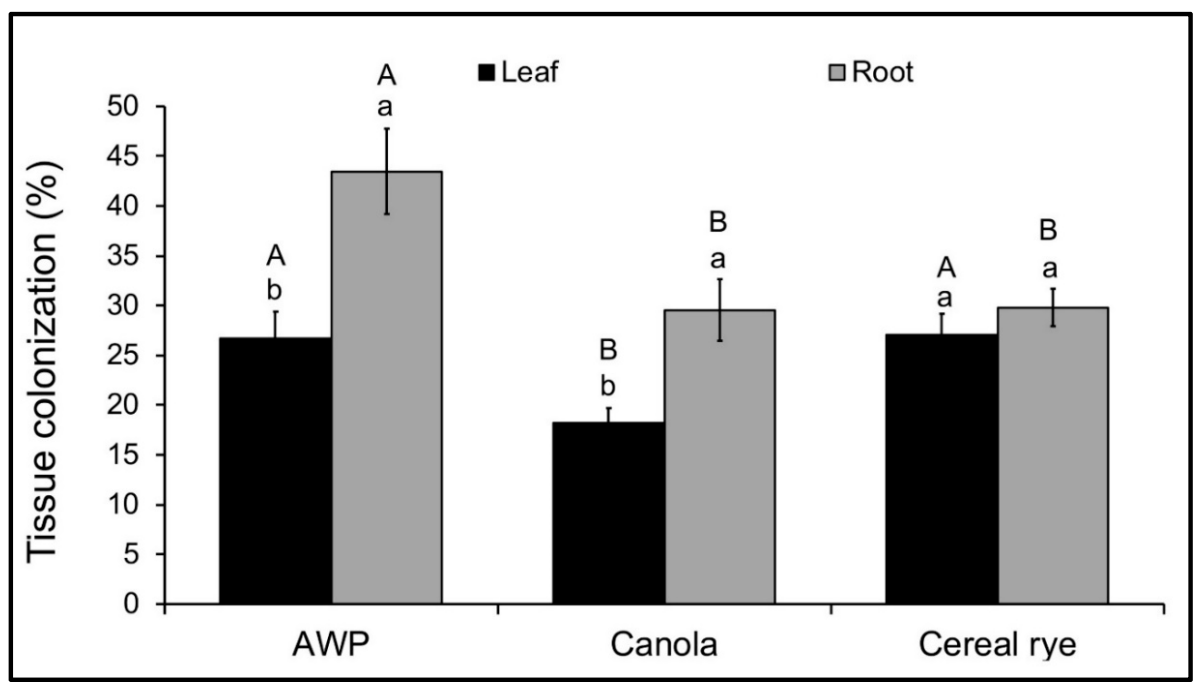

Figure 2. Percentage of root or leaf endophytically colonized in cover crops grown from $M$. robertsii-inoculated seeds of AWP (leaf $n=312$, root $n=312$ ), cereal rye (leaf $n=408$, root $n=408$ ) and canola (leaf $n=306$, root $n=306$ ). Error bars represent \pm standard error of the mean. The lowercase letters show the difference between root and leaf colonization within a cover crop species. The uppercase letters show the differences among cover crop species where leaf or root tissues were analyzed separately. The bars sharing common letters are not significantly different at $p=0.05$.

\subsection{Plant Growth Response to Seed Inoculation with M. robertsii}

The height of AWP plants from the 'Inoculated and Detected' group $(70.98 \pm 1.20 \mathrm{~cm})$ was greater than height of the 'Not Inoculated' control $(68.3 \pm 1.18 \mathrm{~cm})$ plants $\left(p=0.036, F_{2,106}=3.44, n=111\right)$, but was not significantly different from 'Inoculated and Not Detected' plants $(69.40 \pm 1.63 \mathrm{~cm})$ (Figure 3). The height of 'Inoculated and Detected' cereal rye $(38.98 \pm 0.98 \mathrm{~cm})$ was greater than the height of 'Not Inoculated' $(36.13 \pm 1.32 \mathrm{~cm})\left(p=0.03, F_{2,137}=3.54, n=142\right)$ but was not different than the height of 'Inoculated and Not Detected' (37.22 $\pm 1.16 \mathrm{~cm}$ ) (Figure 3). The height of 'Inoculated and Detected' canola plants $(24.16 \pm 0.38 \mathrm{~cm})$ was not significantly different from height of 'Not Inoculated' $(23.22 \pm 0.48 \mathrm{~cm})$ or 'Inoculated and Not Detected' $(23.40 \pm 0.44 \mathrm{~cm})$ plants $\left(p=0.22, F_{2,96}=1.54, n=99\right)$ (Figure 3).

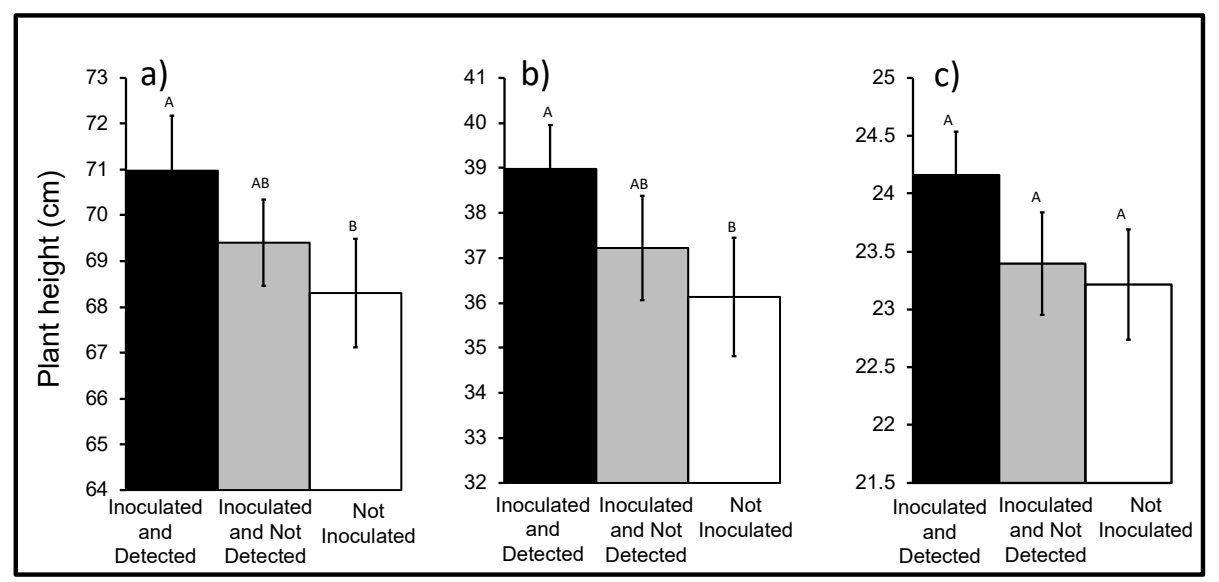

Figure 3. Height of 'Inoculated and Detected' or 'Inoculated and Not Detected' and 'Not Inoculated' (a) AWP $(n=111)$, (b) cereal rye $(n=142)$, and (c) canola $(n=99)$. Error bars represent \pm standard error of the mean. The bars sharing common letters are not significantly different at $p=0.05$. 
Our hypothesis that the level of growth promoting effects would be associated with intensity of colonization was partially supported. We found a relationship between root, but not foliar colonization, and growth promoting effects. In regression analysis to assess the relationship between plant height with the relative proportion of leaf and root tissues from which we recovered endophytic $M$. robertsii, the height of 'Inoculated and Detected' AWP was positively correlated with the proportion of endophytic colonization of root sections $\left(r^{2} A d j=0.06, p=0.01\right.$, estimate $\left.=4.62\right)$ but not leaf sections from which $M$. robertsii was recovered $\left(r^{2} A d j=0.02, p=0.13\right.$, estimate $\left.=4.76\right)$ (Figure 4$)$. The height of 'Inoculated and Detected' cereal rye was positively related to the proportion of root sections from which $M$. robertsii was recovered $\left(r^{2} A d j=0.04, p=0.02\right.$, estimate $\left.=3.49\right)$ but not leaf sections $\left(r^{2} A d j=0.004, p=0.23\right.$, estimate $=2.46)$ (Figure 4$)$. The height of 'Inoculated and Detected' canola plants was not correlated with the proportion of root $\left(r^{2} A d j=-0.001, p=0.35\right.$, estimate $\left.=0.75\right)$ nor leaf sections from which $M$. robertsii was recovered $\left(r^{2} A d j=0.001, p=0.29\right.$, estimate $\left.=2.21\right)$ (Figure 4$)$.

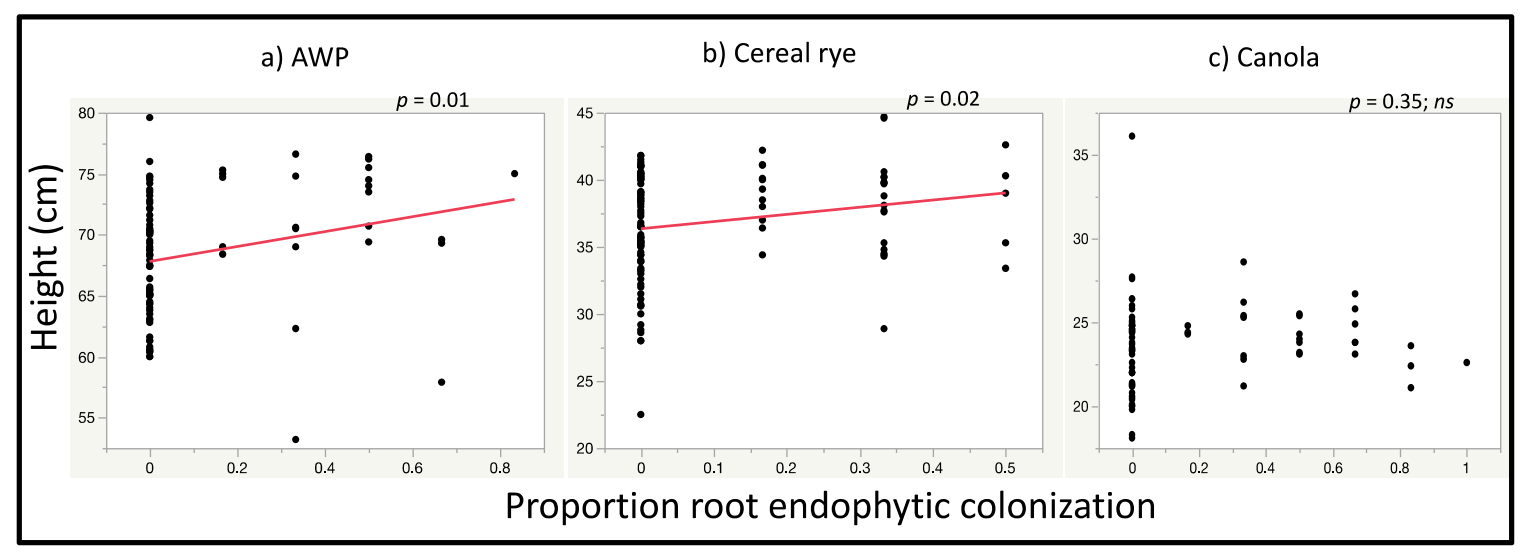

Figure 4. Relationship between the relative proportions of endophytic colonization of root tissue sections from which $M$. robertsii was recovered and height of (a) AWP, (b) cereal rye and (c) canola. No M. robertsii was recovered from non-inoculated control leaf and root tissue sections (data not shown). Regression lines for significant relationships between endophytic colonization and plant height are shown in red.

The above-ground dry biomass of 'Inoculated and Detected' (1.40 $\pm 0.02 \mathrm{~g})$ AWP plants was greater than biomass of 'Not Inoculated' $(1.07 \pm 0.25 \mathrm{~g})$ plants $\left(p=0.02, F_{2,87}=3.94, n=91\right)$, but was not different from the 'Inoculated and Not Detected' (1.18 $\pm 0.09 \mathrm{~g})$ plants (Figure 5). Above-ground dry biomass of 'Inoculated and Detected' $(1.11 \pm 0.09 \mathrm{~g})$ cereal rye plants was greater than the biomass of 'Not Inoculated' $(0.95 \pm 0.13 \mathrm{~g})$ plants $\left(p=0.04, F_{2,109}=3.12, n=113\right)$, but was not different from the 'Inoculated and Not Detected' $(1.06 \pm 0.06 \mathrm{~g})$ plants (Figure 5). The above-ground dry biomass of 'Inoculated and Detected' (1.86 $\pm 0.38 \mathrm{~g})$ canola plants was not different than 'Not Inoculated' $(1.78 \pm 0.42 \mathrm{~g})$ plants and the 'Inoculated and Not Detected' $(1.83 \pm 0.40 \mathrm{~g})$ plants $\left(p=0.40, F_{2,71}=0.92\right.$, $n=75$ ) (Figure 5).

In analyses to assess the correlation of above-ground dry biomass of plants with the proportion of leaf and root sections from which $M$. robertsii was recovered, the above-ground biomass of AWP was positively correlated with the proportion of root sections from which $M$. robertsii was recovered $\left(r^{2}\right.$ Adj $=0.07, p=0.02$, estimate $\left.=0.41\right)$ but not to the proportion of endophytic leaf sections $\left(r^{2}{ }_{\text {Adj }}=0.03\right.$, $p=0.09$, estimate $=0.49$ ) (Figure 6). The above-ground dry biomass of cereal rye was not correlated with the proportion of leaf $\left(r^{2} A d j=0.01, p=0.17\right.$, estimate $\left.=0.22\right)$ or root sections $\left(r^{2} A d j=0.03, p=0.06\right.$, estimate $=0.22$ ) from which $M$. robertsii was recovered (Figure 6 ). Similarly, above-ground dry biomass of canola plants was not correlated with the proportion of leaf $\left(r^{2} A d j=-0.003, p=0.37\right.$, estimate $\left.=0.35\right)$ or root sections $\left(r^{2} A d j=0.008, p=0.23\right.$, estimate $\left.=0.19\right)$ from which $M$. robertsii was recovered (Figure 6). 


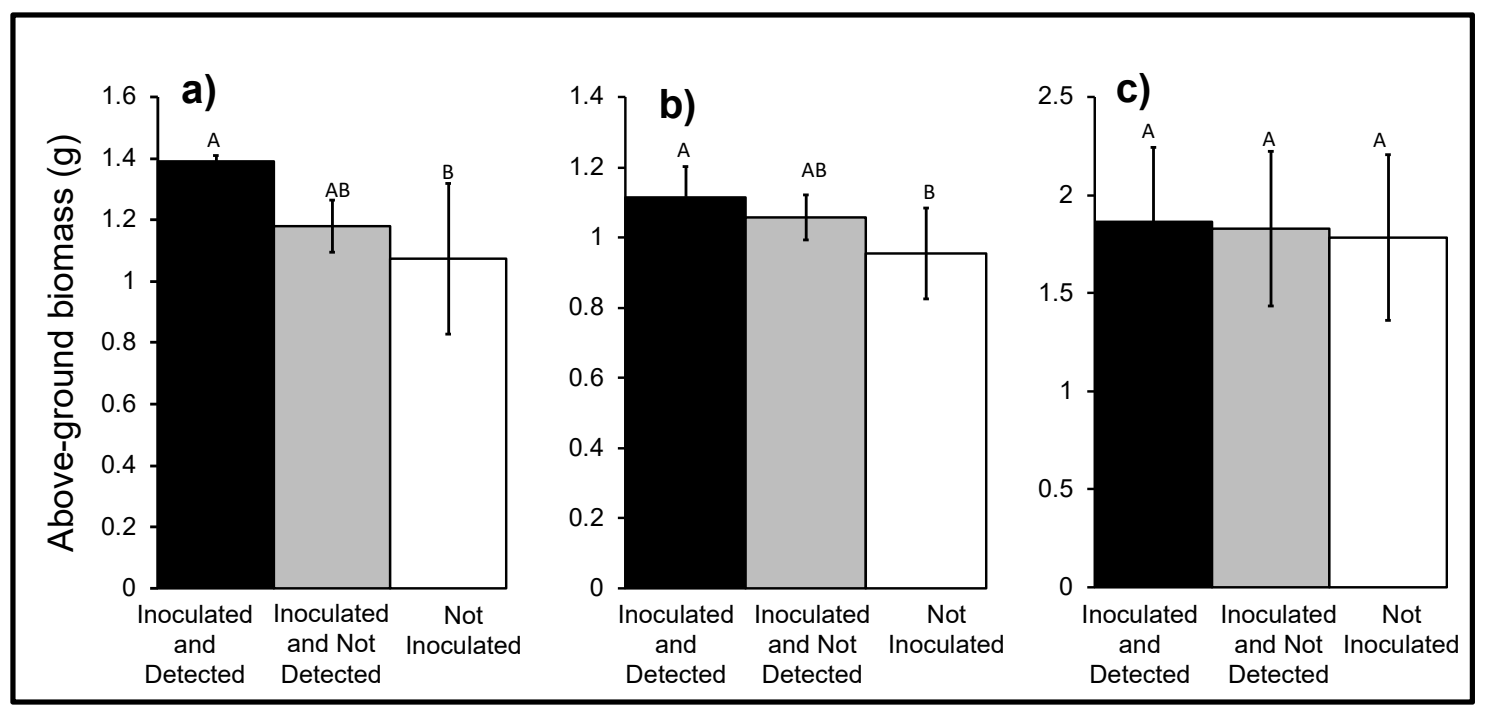

Figure 5. Mean above-ground dry biomass of (a) AWP $(n=91),(\mathbf{b})$ cereal rye $(n=113)$, and (c) canola $(n=75)$ plants. Aboveground biomass was measured at $30 \mathrm{DAG}$ by drying at $60^{\circ} \mathrm{C}$ for $10-14$ days. Error bars represent \pm standard error of the mean. The bars sharing common letters are not significantly different within a cover crop species.

The chlorophyll content of AWP $\left(p=0.3, F_{2,106}=1.22, n=111\right)$, cereal rye $\left(p=0.6, F_{2,137}=1.22\right.$, $n=142)$, and canola $\left(p=0.6, F_{2,96}=0.52, n=99\right)$ in 'Inoculated and Detected' plants was not significantly different from 'Not Inoculated' plants or 'Inoculated and Not Detected' plants (data not shown). Chlorophyll content of AWP, cereal rye, and canola plants grown from M. robertsii-inoculated seeds was not related with the relative proportion of leaf or root sections from which $M$. robertsii was recovered (data not shown).

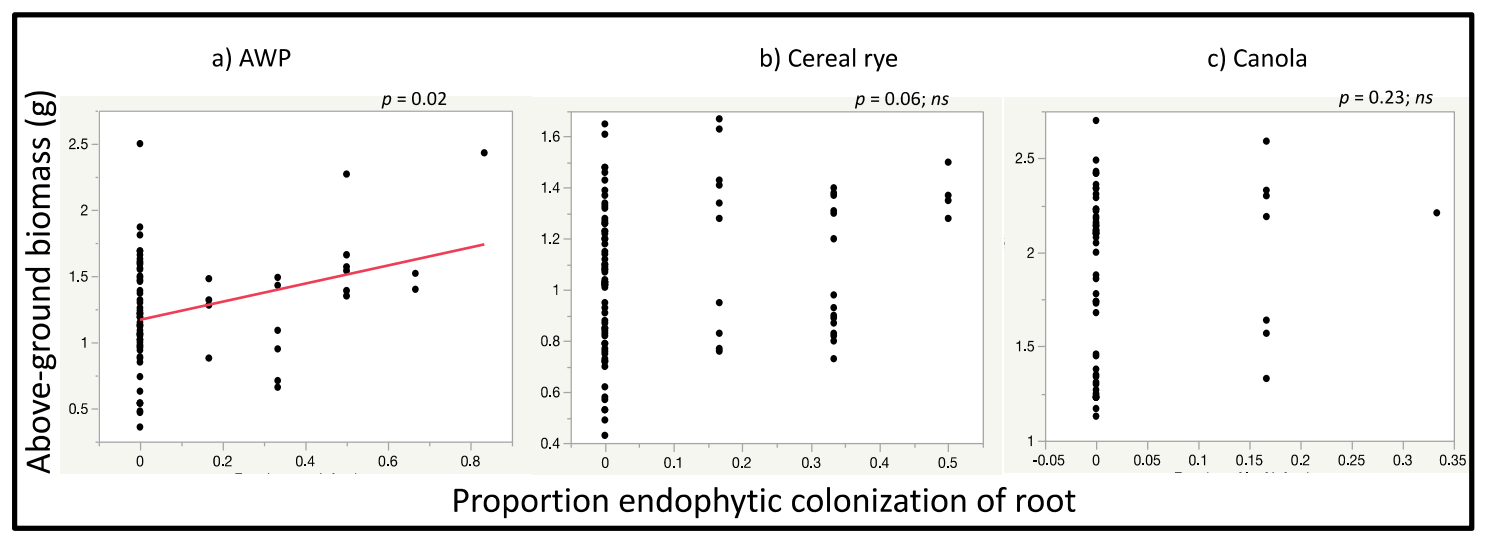

Figure 6. Relationship between the relative proportion of root sections from which $M$. robertsii was recovered and above-ground dry biomass of (a) AWP. There was no relationship between proportion of root sections from which $M$. robertsii was recovered and above-ground dry biomass of (b) cereal rye, and (c) canola. There was no relationship between the relative proportion of leaf sections from which M. robertsii was recovered and above-ground dry biomass of any cover crop species (data not shown). Regression lines for significant relationships between endophytic colonization and plant above-ground biomass are shown in red.

\section{Discussion}

Interest in the use of soil microbes in agroecosystems to promote plant growth and manage insect pests has seen rapid growth over the last decade $[55,56]$. Similarly, research on the effects of endophytic 
entomopathogenic fungi, including Metarhizium spp., on plant performance has become a focus of extensive research since the discovery of their relationship with and beneficial effects on plants $[1,57]$.

We inoculated seeds of winter cover crop species in different plant families with spores of $M$. robertsii to establish endophytic colonization. When colonization of leaf and root tissues were compared within a cover crop species, we found greater colonization of root tissue compared with leaf tissue of Austrian winter pea (AWP) and canola but no difference between root and leaf colonization of cereal rye. For AWP and canola, but not cereal rye, these results partially support our hypothesis that we would detect $M$. robertsii more frequently in root than in leaf tissues. When compared among cover crop species, root colonization in AWP was greater than in cereal rye or canola. Similarly, leaf colonization was greater in AWP and cereal rye than in canola. When we compared overall endophytic colonization among cover crop species, we found greater endophytic colonization in AWP than cereal rye and canola and there was no difference between canola and cereal rye. These results are partially consistent with our previous research in which detection of M. robertsii from field soil in which AWP was grown as a cover crop was greater than those in which canola was grown or where cereal rye predominated in cover crop mixtures [44]. Therefore, our hypothesis that overall colonization of AWP would be greater than in cereal rye, and that colonization of canola would be lowest was partially supported. These differences from field observations may be due to the absence of other belowground biotic interactions or environmental conditions that differed between the relatively controlled conditions in our experiment compared with those interactions and conditions in our field experiment. Our results are consistent with previous reports in which Metarhizium spp. endophytically colonized diverse plant species grown from seed, soil or foliar inoculation. For example, successful endophytic colonization by seed inoculation with $M$. robertsii and M. acridum was achieved in cowpea and cucumber [58]. M. anisopliae endophytically colonized $82.6 \%$ of broad bean plants at 30 days after seed inoculation and 7 days after soil inoculation [16]. Foliar inoculation with $M$. anisopliae resulted in endophytic colonization of $80 \%$ of 4 -week old canola plants [11]. Inoculation with M. robertsii or M. anisopliae established endophytic colonization in tomato [18,59], sorghum [60], tea [61], soybean [23], switchgrass and haricot bean root [6], cauliflower root [62] and cassava root [19]. It appears that $M$. robertsii is a generalist endophyte capable of establishing varying degrees of endophytic colonization in multiple tissues across a broad plant host range that includes many plant families and functional traits.

Our hypothesis that we would detect colonization more frequently in roots compared to foliage was partially supported. The proportion of plants from which we detected only root colonization was not different among the three cover crop species, and detection of endophytic colonization only in roots was greater than colonization only in leaf tissue. However, there was no difference in the proportion of plants in which we detected colonization of only root tissue and of both root and leaf sections. This suggests that some plants for which we detected $M$. robertsii colonization only in root or only leaf tissue may have a localized or transient endophytic colonization that may change over time. Similarly, the plants from which we detected endophytic colonization in both root and leaf tissue may have hosted systemic endophytic colonization $[62,63]$. Because we did not detect $M$. robertsii in any of the control plants, which were randomly located among treated plants, we consider the possibility of foliar infection through horizontal transmission or cross-contamination unlikely.

The method of inoculation may also contribute variability to endophytic colonization. Our study is consistent with previous reports in which Metarhizium spp. colonized plant tissues grown from inoculated seeds. For example, M. anisopliae seed inoculation of Vicia faba, a legume, resulted in endophytic colonization of root tissue at 30 days after inoculation of seed and 7 days after inoculation of soil [16]. The authors only evaluated root tissue of inoculated plants and reported that the degree of colonization in roots differed among tested fungal isolates. Cowpea and cucumber plants grown from seeds inoculated with different $M$. robertsii and M. acridum isolates showed endophytic colonization of both leaf and root tissue [58]. In our study, the method of establishing endophytic M. robertsii by seed inoculation may have supported greater root colonization compared with leaf colonization. Different methods of inoculation have supported establishment of a variable degree of endophytic colonization 
in above- and below-ground plant tissues [64]. Foliar and soil application of M. robertsii or M. anisopliae established endophytic colonization in tomato leaf, stem and root [18,59], sorghum leaf and stem [60], tea leaf and root [61], soybean leaf, stem and root [23], switchgrass and haricot bean root [6], cauliflower root [62] and cassava root [19]. Foliar application of M. anisopliae established up to 80\% endophytic colonization of above-ground tissue in 4-week old canola [11], which is greater than the level of colonization that we observed in leaf tissue by seed inoculation of canola. Foliar application [11] may have resulted in greater endophytic colonization compared with greater root colonization that we observed in our study. Inoculation of tea plants by foliar spray with $M$. anisopliae favored leaf colonization whereas soil inoculation favored root colonization [61]. M. robertsii and M. anisopliae colonized soybean plants systemically following leaf and root immersion, resulting in greater root colonization by root immersion and greater leaf colonization by leaf immersion, but detection of endophytic colonization declined over time [23]. As a predominantly soil-dwelling fungus, we expect that in nature root colonization by Metarhizium spp. would be more common than colonization of other tissues if colonization is mainly localized, but that other tissues could be colonized through systemic colonization.

The degree of endophytic colonization and specific tissue harboring endophytes also varied among different studies. Our results contrast with reports that Metarhizium is exclusively an endophyte of roots $[17,20,22,62]$. We detected $M$. robertsii more frequently in root tissue than in leaf tissue in all plants, but colonization of both root and leaf tissue was common. These results are consistent with studies that report $M$. robertsii or M. anisopliae as an endophyte of stems and leaves as well as roots [11,18,58-61]. Greater colonization and frequency of detection in plant organs near to the inoculation site may help explain greater detection in roots than in leaves [19]. Genotype-specific interactions between endophytes and their host can greatly influence the degree and persistence of endophytic relationship [65]. Increasing our understanding of the factors that control the location of endophytic growth may contribute to the optimization of establishing endophytic growth to exploit the benefits of Metarhizium spp. to plants.

Our hypothesis that the level of growth promoting effects would be associated with intensity of colonization was partially supported. The demonstration in this and other studies of the plant growth-promoting effects of Metarhizium spp. suggests a possible mechanism of growth promotion action $[4,22,25,66,67]$. For example, seed inoculation followed by endophytic root colonization with Metarhizium spp. increased stalk length, ear and foliage biomass of maize, and increased plant height $[10,18,59]$, and maize seeds inoculated with M. anisopliae under field conditions showed an increased stand density, and stalk and foliar fresh weight [29]. The positive effect of endophytic colonization on AWP and cereal rye height and above-ground biomass in our study may be due in part to the contribution of $M$. robertsii to improved nutrient acquisition and assimilation, or production of plant growth promoting auxins $[5,6,24,27]$. As described for Trichoderma spp., plant growth promotion by Metarhizium spp. may be multifactorial [68]. Endophytic M. robertsii did not affect the height and above-ground biomass of canola plants in our study. These results are consistent with previous studies on the effect of brassicas and legumes on soil microbes [69] where plant root exudates and secondary metabolites regulate the fungal rhizosphere community [33,70]. The lack of growth effects on canola and less frequent tissue specific detection of $M$. robertsii in our study could be due to the adverse effects of glucosinolates or other compounds associated with brassicaceous plants [71]. No effect of M. robertsii colonization on growth of canola and positive effects on AWP and cereal rye suggests host-dependent variability of interactions. Plant-specific interactions between endophytes and their host can affect the degree and persistence of endophytic relationship and the subsequent effects on plant growth parameters $[65,68]$.

We did not observe any effect of endophytic colonization on the chlorophyll content of any cover crop species. These results are consistent with our previous study [10] and other studies that report a neutral or negative effect of endophytic colonization on chlorophyll content. For example, in a field experiment, inoculation of maize seeds with $M$. robertsii, M. brunneum and M. anisopliae did not affect 
chlorophyll content [22]. Another study involving foliar application of M. robertsii to sorghum and subsequent re-isolation reported no effect on chlorophyll content or photosynthetic activity [60].

In our study, the regression analysis indicated a weak and partial dose-dependent effect on plant growth promotion in which plant height and above-ground biomass were positively but weakly correlated with the proportion of root, but not leaf, tissues from which endophytic M. robertsii was recovered in AWP, but not cereal rye or canola. These results indicate that higher rates of root colonization may produce greater benefits in some plant species. More intensive endophytic colonization of plants by increasing the inoculum concentration may provide a more pronounced effect on the growth of plants and their ability to withstand stress from herbivory or other environmental factors. Similar studies have explored concentration-dependent responses of endophytic colonization of Metarhizium spp. in host plants. Ahmad et al. [10] observed colonization intensity-dependent effects of $M$. robertsii that resulted in a positive relationship between number of tissue sections endophytically colonized and growth promotion of maize and a negative relationship with growth rate of the black cutworm, Agrotis ipsilon, feeding on endophytic maize foliage. Soil inoculation with M. brunneum showed reduced Fe chlorosis in sorghum plants grown in the calcareous soil inoculated with a higher dose of $5 \times 10^{8}$ conidia $\mathrm{mL}^{-1}$, and the two highest doses $\left(5 \times 10^{6}\right.$ and $5 \times 10^{8}$ conidia mL $\left.{ }^{-1}\right)$ increased plant height and inflorescence production of sunflower grown in both soils as compared to lower doses [72]. Seed inoculation of broad bean with M. brunneum for $16 \mathrm{~h}$ resulted in relatively higher root colonization and greater plant growth than those plants from seeds inoculated for $2 \mathrm{~h}$ or $8 \mathrm{~h} \mathrm{[66].} \mathrm{Those}$ authors reported inconsistent effects on all plant growth parameters measured among inoculation treatments, and they suggested that increasing the seed inoculation duration may provide more time for a greater intensity of endophytic colonization. The duration of seed inoculation, effective fungal spore concentration, the method of inoculation, plant species, isolate diversity and time interval between inoculation and evaluation may be the factors affecting that contribute to the intensity and location of endophytic colonization, and in the varying degree of effects on host plants and insect pests. Because we analyzed only a fraction of each plant to assess the intensity of endophytic colonization, we measured relative levels of colonization. Further research is needed to be able to better assess the level of colonization and if there is an intensity of colonization that may result in negative effects on plants.

\section{Conclusions}

Through seed inoculation, we successfully established systemic colonization of endophytic M. robertsii in three cover crop species that resulted in plant growth-promoting effects. Several challenges remain before this greenhouse-based information can be transferred to the field. For conservation biological control, it would be useful to know what factors influence the establishment of naturally-occurring systemic and localized endophytic colonization in plants. Soil microbial diversity is positively influenced by crop rotation and diversity [73] and adding cover crops to a rotation that can readily host endophytic colonization may help to conserve or increase beneficial microbes, like Metarhizium spp., in the soil microbial community. We suggest that cover crops can help to conserve Metarhizium population between cash crop growing seasons, and perhaps benefit endophytic colonization of cash crops and biological control of pests, but this remains to be tested in the field.

Supplementary Materials: The following are available online at http://www.mdpi.com/2309-608X/6/2/64/s1, Table S1: Supplementary data on endophytic colonization.

Author Contributions: Conceptualization, M.E.B., D.S.L., and M.d.M.J.-G.; methodology, M.E.B., D.S.L., and M.d.M.J.-G.; software, I.A. and M.E.B.; validation, I.A. and M.E.B.; formal analysis, I.A. and M.E.B.; investigation, I.A.; resources, M.E.B.; data curation, I.A.; writing-original draft preparation, I.A. and M.E.B.; writing-review and editing, I.A., M.E.B., D.S.L., and M.d.M.J.-G.; visualization, I.A. and M.E.B.; supervision, M.E.B.; project administration, M.E.B.; funding acquisition, M.E.B., D.S.L., and M.d.M.J.-G. All authors have read and agreed to the published version of the manuscript. 
Funding: This research was funded by USDA National Institute of Food and Agriculture, Organic Transitions (ORG) (No. 2016-51106-25715 and No. 2019-51106-30198) and a Northeast IPM Center Partnership Project grant (No. 73984-10658). The APC was funded by USDA National Institute of Food and Agriculture, Organic Transitions (ORG) (No. 2016-51106-25715).

Acknowledgments: We would like to thank B.M. Bradley, A. Riggle, D.J. Spackman and C. Voortman for technical support and numerous undergraduate lab assistants for their help with data collection. We would like to thank Erin Connolly's lab and Gary Felton's lab for availability of various resources. We thank Scott DiLoreto for greenhouse management and assistance. We thank anonymous reviewers for comments on early versions of the manuscript.

Conflicts of Interest: The authors declare no conflict of interest. The funders had no role in the design of the study; in the collection, analyses, or interpretation of data; in the writing of the manuscript, or in the decision to publish the results.

\section{References}

1. Vega, F.E. The use of fungal entomopathogens as endophytes in biological control: A review. Mycologia 2018, 110, 4-30. [CrossRef]

2. St. Leger, R.J. Studies on adaptations of Metarhizium anisopliae to life in the soil. J. Invertebr. Pathol. 2008, 98, 271-276. [CrossRef] [PubMed]

3. Pava-Ripoll, M.; Angelini, C.; Fang, W.; Wang, S.; Posada, F.J.; St. Leger, R.J. The rhizosphere-competent entomopathogen Metarhizium anisopliae expresses a specific subset of genes in plant root exudate. Microbiology 2011, 157, 47-55. [CrossRef] [PubMed]

4. Raya-Diaz, S.; Sanchez-Rodriguez, A.R.; Segura-Fernandez, J.M.; del Campillo, M.D.; Quesada-Moraga, E. Entomopathogenic fungi-based mechanisms for improved Fe nutrition in sorghum plants grown on calcareous substrates. PLoS ONE 2017, 12, e0185903. [CrossRef]

5. Behie, S.W.; Moreira, C.C.; Sementchoukova, I.; Barelli, L.; Zelisko, P.M.; Bidochka, M.J. Carbon translocation from a plant to an insect-pathogenic endophytic fungus. Nat. Commun. 2017, 8, 14245. [CrossRef] [PubMed]

6. Behie, S.W.; Zelisko, P.M.; Bidochka, M.J. Endophytic insect-parasitic fungi translocate nitrogen directly from insects to plants. Science 2012, 336, 1576-1577. [CrossRef] [PubMed]

7. Jaber, L.R. Grapevine leaf tissue colonization by the fungal entomopathogen Beauveria bassiana s.l. and its effect against downy mildew. BioControl 2015, 60, 103-112. [CrossRef]

8. Jaber, L.R.; Enkerli, J. Fungal entomopathogens as endophytes: Can they promote plant growth? Biocontrol Sci. Technol. 2017, 27, 28-41. [CrossRef]

9. Sasan, R.K.; Bidochka, M.J. Antagonism of the endophytic insect pathogenic fungus Metarhizium robertsii against the bean plant pathogen Fusarium solani f. sp. phaseoli. Can. J. Plant Pathol. 2013, 35, 288-293. [CrossRef]

10. Ahmad, I.; Jiménez-Gasco, M.d.M.; Luthe, D.S.; Shakeel, S.N.; Barbercheck, M.E. Endophytic Metarhizium robertsii promotes maize growth, suppresses insect growth, and alters plant defense gene expression. Biol. Control 2020, 144, 104167. [CrossRef]

11. Batta, Y.A. Efficacy of endophytic and applied Metarhizium anisopliae (Metch.) Sorokin (Ascomycota: Hypocreales) against larvae of Plutella xylostella L. (Yponomeutidae: Lepidoptera) infesting Brassica napus plants. Crop Protect. 2013, 44, 128-134. [CrossRef]

12. Lopez, D.C.; Sword, G.A. The endophytic fungal entomopathogens Beauveria bassiana and Purpureocillium lilacinum enhance the growth of cultivated cotton (Gossypium hirsutum) and negatively affect survival of the cotton bollworm (Helicoverpa zea). Biol. Control 2015, 89, 53-60. [CrossRef]

13. Meyling, N.V.; Eilenberg, J. Ecology of the entomopathogenic fungi Beauveria bassiana and Metarhizium anisopliae in temperate agroecosystems: Potential for conservation biological control. Biol. Control 2007, 43, 145-155. [CrossRef]

14. Steinwender, B.M.; Enkerli, J.; Widmer, F.; Eilenberg, J.; Meyling, N.V. Molecular diversity of the Metarhizium anisopliae lineage in an agricultural field. IOBC/wprs Bulletin 2011, 66, 113-115.

15. Tiago, P.V.; de Oliveira, N.T.; Lima, E.A.D.A. Biological insect control using Metarhizium anisopliae: Morphological, molecular, and ecological aspects. Cienc. Rural 2014, 44, 645-651. [CrossRef]

16. Akello, J.; Sikora, R. Systemic acropedal influence of endophyte seed treatment on Acyrthosiphon pisum and Aphis fabae offspring development and reproductive fitness. Biol. Control 2012, 61, 215-221. [CrossRef] 
17. Behie, S.W.; Jones, S.J.; Bidochka, M.J. Plant tissue localization of the endophytic insect pathogenic fungi Metarhizium and Beauveria. Fungal Ecol. 2015, 13, 112-119. [CrossRef]

18. Elena, G.J.; Beatriz, P.J.; Alejandro, P.; Lecuona, R. Metarhizium anisopliae (Metschnikoff) Sorokin promotes growth and has endophytic activity in tomato plants. Adv. Biol. Res. 2011, 5, 22-27.

19. Greenfield, M.; Gomez-Jimenez, M.I.; Ortiz, V.; Vega, F.E.; Kramer, M.; Parsa, S. Beauveria bassiana and Metarhizium anisopliae endophytically colonize cassava roots following soil drench inoculation. Biol. Control 2016, 95, 40-48. [CrossRef]

20. Sasan, R.K.; Bidochka, M.J. The insect-pathogenic fungus Metarhizium robertsii (Clavicipitaceae) is also an endophyte that stimulates plant root development. Am. J. Bot. 2012, 99, 101-107. [CrossRef]

21. Barelli, L.; Moreira, C.C.; Bidochka, M.J. Initial stages of endophytic colonization by Metarhizium involves rhizoplane colonization. Microbiology 2018, 164, 1531-1540. [CrossRef] [PubMed]

22. Liao, X.G.; O'Brien, T.R.; Fang, W.G.; St. Leger, R.J. The plant beneficial effects of Metarhizium species correlate with their association with roots. Appl. Microbiol. Biotechnol. 2014, 98, 7089-7096. [CrossRef] [PubMed]

23. Russo, M.L.; Pelizza, S.; Vianna, M.; Allegrucci, N.; Cabello, M.N.; Toledo, A.V.; Mourelos, C.; Scorsetti, A.C. Effect of endophytic entomopathogenic fungi on soybean Glycine max (L.) Merr. growth and yield. J. King Saud Univ. Sci. 2018, 31, 728-736. [CrossRef]

24. Krell, V.; Jakobs-Schoenwandt, D.; Vidal, S.; Patel, A.V. Encapsulation of Metarhizium brunneum enhances endophytism in tomato plants. Biol. Control 2018, 116, 62-73. [CrossRef]

25. Jaber, L.R.; Alananbeh, K.M. Fungal entomopathogens as endophytes reduce several species of Fusarium causing crown and root rot in sweet pepper (Capsicum annuum L.). Biol. Control 2018, 126, 117-126. [CrossRef]

26. Liu, S.F.; Wang, G.J.; Nong, X.Q.; Liu, B.; Wang, M.M.; Li, S.L.; Cao, G.C.; Zhang, Z.H. Entomopathogen Metarhizium anisopliae promotes the early development of peanut root. Plant Protect. Sci. 2017, 53, 101-107.

27. Liao, X.G.; Lovett, B.; Fang, W.G.; St. Leger, R.J. Metarhizium robertsii produces indole-3-acetic acid, which promotes root growth in Arabidopsis and enhances virulence to insects. Microbiology 2017, 163, 980-991. [CrossRef]

28. Jaber, L.R.; Araj, S.E. Interactions among endophytic fungal entomopathogens (Ascomycota: Hypocreales), the green peach aphid Myzus persicae Sulzer (Homoptera: Aphididae), and the aphid endoparasitoid Aphidius colemani Viereck (Hymenoptera: Braconidae). Biol. Control 2018, 116, 53-61. [CrossRef]

29. Kabaluk, J.T.; Ericsson, J.D. Metarhizium anisopliae seed treatment increases yield of field corn when applied for wireworm control. Agron. J. 2007, 99, 1377-1381. [CrossRef]

30. Berg, G.; Smalla, K. Plant species and soil type cooperatively shape the structure and function of microbial communities in the rhizosphere. FEMS Microbiol. Ecol. 2009, 68, 1-13. [CrossRef]

31. Fernandez, A.L.; Sheaffer, C.C.; Wyse, D.L.; Staley, C.; Gould, T.J.; Sadowsky, M.J. Structure of bacterial communities in soil following cover crop and organic fertilizer incorporation. Appl. Microbiol. Biotechnol. 2016, 100, 9331-9341. [CrossRef] [PubMed]

32. Tiemann, L.K.; Grandy, A.S.; Atkinson, E.E.; Marin-Spiotta, E.; McDaniel, M.D. Crop rotational diversity enhances belowground communities and functions in an agroecosystem. Ecol. Lett. 2015, 18, 761-771. [CrossRef]

33. Broeckling, C.D.; Broz, A.K.; Bergelson, J.; Manter, D.K.; Vivanco, J.M. Root exudates regulate soil fungal community composition and diversity. Appl. Environ. Microbiol. 2008, 74, 738-744. [CrossRef] [PubMed]

34. Hu, G.; St. Leger, R.J. Field studies using a recombinant mycoinsecticide (Metarhizium anisopliae) reveal that it is rhizosphere competent. Appl. Environ. Microbiol. 2002, 68, 6383-6387. [CrossRef] [PubMed]

35. Wyrebek, M.; Huber, C.; Sasan, R.K.; Bidochka, M.J. Three sympatrically occurring species of Metarhizium show plant rhizosphere specificity. Microbiology 2011, 157, 2904-2911. [CrossRef]

36. Steinwender, B.M.; Enkerli, J.; Widmer, F.; Eilenberg, J.; Kristensen, H.L.; Bidochka, M.J.; Meyling, N.V. Root isolations of Metarhizium spp. from crops reflect diversity in the soil and indicate no plant specificity. J. Invertebr. Pathol. 2015, 132, 142-148. [CrossRef]

37. Alvarez, R.; Steinbach, H.S.; De Paepe, J.L. Cover crop effects on soils and subsequent crops in the pampas: A meta-analysis. Soil Tillage Res. 2017, 170, 53-65. [CrossRef]

38. Blanco-Canqui, H.; Shaver, T.M.; Lindquist, J.L.; Shapiro, C.A.; Elmore, R.W.; Francis, C.A.; Hergert, G.W. Cover crops and ecosystem services: Insights from studies in temperate soils. Agron. J. 2015, 107, 2449-2474. [CrossRef] 
39. Finney, D.M.; White, C.M.; Kaye, J.P. Biomass production and carbon/nitrogen ratio influence ecosystem services from cover crop mixtures. Agron. J. 2016, 108, 39-52. [CrossRef]

40. Schipanski, M.E.; Barbercheck, M.; Douglas, M.R.; Finney, D.M.; Haider, K.; Kaye, J.P.; Kemanian, A.R.; Mortensen, D.A.; Ryan, M.R.; Tooker, J.; et al. A framework for evaluating ecosystem services provided by cover crops in agroecosystems. Agr. Syst. 2014, 125, 12-22. [CrossRef]

41. White, C.M.; DuPont, S.T.; Hautau, M.; Hartman, D.; Finney, D.M.; Bradley, B.; LaChance, J.C.; Kaye, J.P. Managing the trade off between nitrogen supply and retention with cover crop mixtures. Agr. Ecosyst. Environ. 2017, 237, 121-133. [CrossRef]

42. Murrell, E.G.; Schipanski, M.E.; Finney, D.M.; Hunter, M.C.; Burgess, M.; LaChance, J.C.; Baraibar, B.; White, C.M.; Mortensen, D.A.; Kaye, J.P. Achieving diverse cover crop mixtures: Effects of planting date and seeding rate. Agron. J. 2017, 109, 259-271. [CrossRef]

43. Jabbour, R.; Barbercheck, M.E. Soil management effects on entomopathogenic fungi during the transition to organic agriculture in a feed grain rotation. Biol. Control 2009, 51, 435-443. [CrossRef]

44. Randhawa, P.K.; Mullen, C.; Barbercheck, M. Plant identity, but not diversity, and agroecosystem characteristics affect the occurrence of $M$. robertsii in an organic cropping system. Biol. Control 2018, 124, 18-29. [CrossRef]

45. Boetel, M.A.; Majumdar, A.; Jaronski, S.T.; Horsley, R.D. Cover crop and conidia delivery system impacts on soil persistence of Metarhizium anisopliae (Hypocreales: Clavicipitaceae) in sugarbeet. Biocontrol Sci. Technol. 2012, 22, 1284-1304. [CrossRef]

46. Pell, J.K.; Hannam, J.J.; Steinkraus, D.C. Conservation biological control using fungal entomopathogens. BioControl 2010, 55, 187-198. [CrossRef]

47. USDA. National Organic Standards. Available online: https://www.ams.usda.gov/rules-regulations/organic (accessed on 24 March 2020).

48. Zimmermann, G. The 'Galleria bait method' for detection of entomopathogenic fungi in soil. J. Appl. Entomol. 1986, 102, 213-215. [CrossRef]

49. Fernandes, E.K.K.; Keyser, C.A.; Rangel, D.E.N.; Foster, R.N.; Roberts, D.W. CTC medium: A novel dodine-free selective medium for isolating entomopathogenic fungi, especially Metarhizium acridum, from soil. Biol. Control 2010, 54, 197-205. [CrossRef]

50. Bischoff, J.F.; Rehner, S.A.; Humber, R.A. A multilocus phylogeny of the Metarhizium anisopliae lineage. Mycologia 2009, 101, 512-530. [CrossRef]

51. Kepler, R.M.; Ugine, T.A.; Maul, J.E.; Cavigelli, M.A.; Rehner, S.A. Community composition and population genetics of insect pathogenic fungi in the genus Metarhizium from soils of a long-term agricultural research system. Environ. Microbiol. 2015, 17, 2791-2804. [CrossRef]

52. Parsa, S.; Ortiz, V.; Vega, F.E. Establishing fungal entomopathogens as endophytes: Towards endophytic biological control. Jove-J. Vis. Exp. 2013, 74, e50360. [CrossRef] [PubMed]

53. Cenis, J.L. Rapid extraction of fungal DNA for PCR amplification. Nucleic Acids Res. 1992, 20, 2380. [CrossRef] [PubMed]

54. Ives, A.R. For testing the significance of regression coefficients, go ahead and log-transform count data. Methods Ecol. Evol. 2015, 6, 828-835. [CrossRef]

55. Ahmad, I.; Zaib, S.; Alves, P.C.M.S.; Luthe, D.S.; Bano, A.; Shakeel, S.N. Molecular and physiological analysis of drought stress responses in Zea mays treated with plant growth promoting rhizobacteria. Biol. Plant. 2019, 63, 536-547. [CrossRef]

56. Sergaki, C.; Lagunas, B.; Lidbury, I.; Gifford, M.L.; Schafer, P. Challenges and approaches in microbiome research: From fundamental to applied. Front. Plant Sci. 2018, 9, 1205. [CrossRef]

57. Bing, L.A.; Lewis, L.C. Suppression of Ostrinia nubilalis (Hübner)(Lepidoptera: Pyralidae) by endophytic Beauveria bassiana (Balsamo) Vuillemin. Environ. Entomol. 1991, 20, 1207-1211. [CrossRef]

58. Golo, P.S.; Gardner, D.R.; Grilley, M.M.; Takemoto, J.Y.; Krasnoff, S.B.; Pires, M.S.; Fernandes, E.K.; Bittencourt, V.R.; Roberts, D.W. Production of destruxins from Metarhizium spp. fungi in artificial medium and in endophytically colonized cowpea plants. PLoS ONE 2014, 9, e104946. [CrossRef]

59. Dutta, P.; Kaushik, H.; Bhawmick, P.; Puzari, K.; Hazarika, G. Metarhizium anisopliae as endophyte has the ability of plant growth enhancement. Int. J. Curr. Res. 2015, 7, 14300-14304. 
60. Mantzoukas, S.; Chondrogiannis, C.; Grammatikopoulos, G. Effects of three endophytic entomopathogens on sweet sorghum and on the larvae of the stalk borer Sesamia nonagrioides. Entomol. Exp. Appl. 2015, 154, 78-87. [CrossRef]

61. Kaushik, H.; Dutta, P. Establishment of Metarhizium anisopliae, an entomopathogen as endophyte for biological control in tea. Res. Crop 2016, 17, 375-387. [CrossRef]

62. Razinger, J.; Lutz, M.; Schroers, H.J.; Urek, G.; Grunder, J. Evaluation of insect associated and plant growth promoting fungi in the control of cabbage root flies. J. Econ. Entomol. 2014, 107, 1348-1354. [CrossRef] [PubMed]

63. Keyser, C.A.; Thorup-Kristensen, K.; Meyling, N.V. Metarhizium seed treatment mediates fungal dispersal via roots and induces infections in insects. Fungal Ecol. 2014, 11, 122-131. [CrossRef]

64. Hyde, K.D.; Soytong, K. The fungal endophyte dilemma. Fungal Divers. 2008, 33, 163-173.

65. Saikkonen, K.; Wali, P.R.; Helander, M. Genetic compatibility determines endophyte-grass combinations. PLoS ONE 2010, 5, e11395. [CrossRef]

66. Jaber, L.R.; Enkerli, J. Effect of seed treatment duration on growth and colonization of Vicia faba by endophytic Beauveria bassiana and Metarhizium brunneum. Biol. Control 2016, 103, 187-195. [CrossRef]

67. Khan, A.L.; Hamayun, M.; Khan, S.A.; Kang, S.M.; Shinwari, Z.K.; Kamran, M.; Ur Rehman, S.; Kim, J.G.; Lee, I.J. Pure culture of Metarhizium anisopliae LHL07 reprograms soybean to higher growth and mitigates salt stress. World J. Microbiol. Biotechnol. 2012, 28, 1483-1494. [CrossRef]

68. Mukherjee, P.K.; Horwitz, B.A.; Herrera-Estrella, A.; Schmoll, M.; Kenerley, C.M. Trichoderma research in the genome era. Annu. Rev. Phytopathol. 2013, 51, 105-129. [CrossRef]

69. Vukicevich, E.; Lowery, T.; Bowen, P.; Urbez-Torres, J.R.; Hart, M. Cover crops to increase soil microbial diversity and mitigate decline in perennial agriculture. A review. Agron. Sustain. Dev. 2016, 36, 48. [CrossRef]

70. Biate, D.L.; Kumari, A.; Annapurna, K.; Kumar, L.V.; Ramadoss, D.; Reddy, K.K.; Naik, S. Legume root exudates: Their role in symbiotic interactions. In Plant Microbes Symbiosis: Applied Facets; Springer: Berlin, Germany, 2015; pp. 259-271.

71. von Roepenack-Lahaye, E.; Degenkolb, T.; Zerjeski, M.; Franz, M.; Roth, U.; Wessjohann, L.; Schmidt, J.; Scheel, D.; Clemens, S. Profiling of Arabidopsis secondary metabolites by capillary liquid chromatography coupled to electrospray ionization quadrupole time-of-flight mass spectrometry. Plant Physiol. 2004, 134, 548-559. [CrossRef]

72. Raya-Diaz, S.; Quesada-Moraga, E.; Barron, V.; del Campillo, M.C.; Sanchez-Rodriguez, A. Redefining the dose of the entomopathogenic fungus Metarhizium brunneum (Ascomycota, Hypocreales) to increase Fe bioavailability and promote plant growth in calcareous and sandy soils. Plant Soil 2017, 418, 387-404. [CrossRef]

73. Venter, Z.S.; Jacobs, K.; Hawkins, H.J. The impact of crop rotation on soil microbial diversity: A meta-analysis. Pedobiologia 2016, 59, 215-223. [CrossRef]

(C) 2020 by the authors. Licensee MDPI, Basel, Switzerland. This article is an open access article distributed under the terms and conditions of the Creative Commons Attribution (CC BY) license (http://creativecommons.org/licenses/by/4.0/). 